\title{
Relationship Between Isokinetic Leg Strength and Dynamic Balance Performance of Elite Male Volleyball Players
}

\author{
Yakup Aktaş \\ Correspondence: Yakup Aktaş, School of Physical Education and Sports, Harran University, Şanlıurfa, Turkey.
}

Received: May 8, 2019

doi:10.11114/jets.v7i7.4328

Accepted: June 2, 2019

Online Published: June 17, 2019

URL: https://doi.org/10.11114/jets.v7i7.4328

\begin{abstract}
Objective: This study aims at analysing the relationship between isokinetic leg strength and dynamic balance performances of MSK Urfa male volleyball players that play in Turkey Volleyball League of Swashbucklers.

Materials and Methods: 13 voluntary volleyball players that played in MSK Urfa being a team in League of Swashbucklers in 2016-2017 season participated in the study. Bioelectric Impedance Measurement Device (Tanita MC 180) was used to measure body composition of volleyball players. Isokinetic dynamometer (IsoMed $2000 \mathrm{GmbH}$, Germany) was used to measure their isokinetic leg strength. Tecnobody Prokin device was used to measure their dynamic balance performance. The relationship between isokinetic leg strength and dynamic balance performance was determined by Spearman correlation analysis and the significance level was accepted as $p<0.05$.

Findings: According to the data obtained from the study, there was no statistically significant relationship between the dynamic balance performance of volleyball players and the bilateral differences of quadriceps and hamstring muscles at the angular velocity of $60^{\circ} / \mathrm{s}(\mathrm{p}>0,05)$; but there was statistically significant relationship between the bilateral differences of quadriceps and hamstring muscles at the angular velocity of $120^{\circ} / \mathrm{s}(\mathrm{p}<0,05)$. There was no statistically significant relationship between dynamic balance performance and Hamstring/Quadriceps (H/Q) force ratio of dominant and non-dominant leg at angular velocity of $60 \%$ and $120 \% \mathrm{~s}(\mathrm{p}>0.05)$.
\end{abstract}

As a result; it was observed that the bilateral differences of hamstring and quadriceps muscles of volleyball players at $120 \%$ s velocity affected their dynamic balance performance; but H/Q ratio at $60 \%$ s and $120 \%$ s velocity did not affect their dynamic balance performance.

Keywords: volleyball, isokinetic, leg strength, dynamic balance

\section{Introduction}

Volleyball is a branch that includes in spike, block, spike serve and coverage actions, is played in high intensity in a short span of time, and requires maintaining body balance as well as strong arms and leg.

Volleyball players need to gain strength and maintain it to perform successfully. They need to provide the control of the body in a proper mechanic while falling down after the spike and block; in other words, they need to have balance control, as well as maintaining the power gained (Sayers, 2000).

Balance is of great importance for the performances of sportsmen. All branches contain a certain balance in their techniques. Studies conducted link the weakness of balance performance in both male and female athletes with an increased risk of lower extremity injury (Pappas et al., 2007; Hewett et al., 2009; Foss et al., 2014; Matthews et al., 2016). It was determined that strength, flexibility and plyometric studies in which balance exercises constitute joint component lead to decrease in knee injuries by $72 \%$ for volleyball, basketball and football players (Hewett et al., 1999). There are some studies reporting a close relationship between balance and force development in the literature (Soyuer et al., 2006; Mohammadi et al., 2012; Moraru et al. 2014; Çelenk et al. 2015; Bulgay and Polat 2017).

Muscle strength is one of the most important components of sport for both injury prevention and high performance (Magalhaes et al., 2004). While measuring muscle strength, it is quite important to determine the muscle balance and strength between dominant / non-dominant and agonist / antagonist muscle groups (Derviseviç and Hadzic, 2012). Isokinetic dynamometers are widely used in these measurements (Kong and Burns, 2010). Isokinetic tests are conducted at many different speeds (30-60-90-120-180-240-300\%) (Rosene et al., 2001). While the measurements between 0-180 /s measure basic muscle strength, measurements at a speed higher than $180 \%$ measure muscle functional force 
(Willigenburg et al., 2015).

The difference in muscle strength of the same muscle group in different extremities is bilateral difference. Bilateral differences (90\%) accepted in the literature are in the limits of (90\%). The strength values of the dominant leg is slightly higher between the dominant and non-dominant legs (islegen et al., 1989).

When analyzed in the literature, there are some studies that show the the relationship between the dominant and non-dominant hamstring and quadriceps muscle strength and balance (Mohammadi et al., 2012; Moraru et al., 2014; Çelenk et al., 2015; İbiş et al., 2015; Bulgay and Polat 2017; Akarçeşme and Aktuğ, 2018). While there are some isokinetic leg forces studies at different angular velocities in the literature, this study aims at investigating the relationship between H/Q dominant- non-dominant Hamstring/Quadriceps (H/Q) bilateral differences of leg forces of volleyball players at angular velocities of both $60 \%$ and $180 \%$ and the dynamic balance.

\section{Method}

\subsection{Participant}

Thirteen volunteer male volleyball players that played in MSK URFA being a team in League of Swashbucklers in Turkish Volleyball Federation in 2016-2017 season are samples of the study. The average age, height, body weight and body mass index of the volleyball players participating in the study are shown in Table 1.

Table 1. Average age, height, body weight and body mass index of volleyball players

\begin{tabular}{lc}
\hline Parameter & $\mathbf{X} \pm$ Ss \\
Age (year) & $26,50 \pm 4,10$ \\
Height $(\mathbf{c m})$ & $195,67 \pm 5,38$ \\
Weight $(\mathbf{k g})$ & $87,54 \pm 7,12$ \\
BMI & $22,85 \pm 1,32$
\end{tabular}

Since the team was in Ankara during the preparation camp period, isokinetic leg muscle strength, balance measurements and anthropometric measurements of volleyball players were performed in Ankara Private Guven Hospital.

\subsection{Data Collection and Data Collection Tolls}

Isokinetic leg muscle strength, balance measurements and anthropometric measurements of volleyball players were performed at the Ankara Private Guven hospital at the beginning of 2016-2017 pre-season preparation stage.

\section{Isokinetic Leg Strength Measurement}

Isokinetic leg strength of volleyball players were measured with isokinetic dynamometer (IsoMed $2000 \mathrm{GmbH}$, Germany). Before the test, the players warmed up at $80-90 \mathrm{rpm}$ speed at the bicycle ergometer and then they performed stretching exercises. During the test, the body and knee parts of all volleyball players were fixed to the device by means of tapes, and isokinetic leg strength consisting of five repetitions at the angular velocity of $60 \%$ and 10 repetitions at the angular velocity of $120 \%$ were performed on both legs. Before the test started, one trial was performed at both angular speeds.

\section{Dynamic Balance}

Tecnobody Prokin (Italy) device was used to determine the dynamic balance performance of the volleyball players participated in the study. In the dynamic balance evaluation, the person was asked to keep the balance by standing on both feet on moving platform, by standing in straight position and in double foot squat position for 25 seconds. Before the test, some re-tests consisting of 10 seconds each were conducted on sportsmen to adapt to the dynamic balance tests.

\section{BIA Measurement}

Body composition measurements of volleyball players were performed with Bioelectric Impedance Measurement Device (Tanita MC 180).

\subsection{Data Analysis}

Descriptive statistical procedures (mean, standard deviation) were applied to the obtained data. Correlation coefficients and statistical significance were evaluated by Spearman Correlation Test since the variables were not normally distributed in the relationship between voluntary players' isokinetic leg strength and dynamic balance performance. The results were evaluated in SPSS 23.0 package program and the significance level was accepted as $\mathrm{p}<0.05$. 


\section{Findings}

The dominant, non-dominant bilateral differences of volleyball players at angular velocities of $60 \% \mathrm{~s} / \mathrm{Q}$ force averages, $\mathrm{H} / \mathrm{Q}$ ratios are shown in Table 2.

Table 2. Average of Hamstring and Quadriceps, H/Q and Hamstring and Quadriceps Bilateral Differences of Volleyball Players' Dominant and Non-dominant Legs at $60 \%$ s Angular Speeds

\begin{tabular}{|c|c|}
\hline Parameters & $\mathrm{X} \pm \mathrm{Ss}$ \\
\hline Dominant $60^{\circ} / \mathrm{s}$ quadriceps $(\mathrm{kg})$ & $206,42 \pm 21,45$ \\
\hline Dominant $60 \%$ s hamstring $(\mathrm{kg})$ & $144,92 \pm 21,78$ \\
\hline Nondominant $60^{\circ} / \mathrm{s}$ quadriceps $(\mathrm{kg})$ & $180,08 \pm 35,72$ \\
\hline Nondominant $60^{\circ} / \mathrm{s}$ hamstring $(\mathrm{kg})$ & $138,08 \pm 23,61$ \\
\hline Dominant $60 \% / \mathrm{s} / \mathrm{Q}$ & $0,69 \pm 0,08$ \\
\hline Nondominant $60^{\circ} / \mathrm{s} \mathrm{H} / \mathrm{Q}$ & $0,77 \pm 0,16$ \\
\hline Bilateral $60^{\circ} / \mathrm{s}$ quadriceps & $\% 118 \pm 22,4$ \\
\hline Bilateral $60^{\circ} / \mathrm{s}$ hamstring & $\% 110 \pm 11,2$ \\
\hline
\end{tabular}

H/Q: Hamstring/Quadriceps

The dominant, non-dominant bilateral differences of volleyball players at angular velocities of $120^{\circ} / \mathrm{s} \mathrm{H} / \mathrm{Q}$ force averages, $\mathrm{H} / \mathrm{Q}$ ratios are shown in Table 3.

Table 3. Means of Hamstring and Quadriceps, H/Q and Hamstring and Quadriceps Bilateral Differences of Dominant and Non-dominant Legs of Volleyball Players at $120 \%$ s Angular Speeds

\begin{tabular}{lc}
\hline Parameters & $\mathbf{X} \pm \mathbf{S d}$ \\
\hline Dominant $\mathbf{1 2 0} / \mathbf{s}$ quadriceps $(\mathbf{k g})$ & $191,42 \pm 37,80$ \\
Dominant $\mathbf{1 2 0} / \mathbf{s}$ hamstring $(\mathbf{k g})$ & $124,42 \pm 29,12$ \\
Nondominant $\mathbf{1 2 0} /$ s quadriceps $(\mathbf{k g})$ & $164,50 \pm 36,73$ \\
Nondominant $\mathbf{1 2 0} / \mathbf{s}$ hamstring $(\mathbf{k g})$ & $119,58 \pm 27,13$ \\
Dominant $\mathbf{1 2 0} \% \mathbf{s ~ H / Q}$ & $0,64 \pm 0,10$ \\
Nondominant 120$/ \mathbf{s ~ H} / \mathbf{Q}$ & $0,73 \pm 0,14$ \\
Bilateral $\mathbf{1 2 0} / \mathbf{s}$ quadriceps & $\% 118 \pm 17,60$ \\
Bilateral $\mathbf{1 2 0} / \mathbf{s}$ hamstring & $\% 111 \pm 7,09$ \\
\hline
\end{tabular}

H/Q: Hamstring/Quadriceps

The results of the study that was conducted to investigate the relationship between dynamic balance performance and isokinetic leg forces of volleyball players are shown in Table 4 and Table 5.

Table 4. The Relationship Between Bilateral Differences of Hamstring and Quadriceps Muscles and Dynamic Balance Performance of the Dominant and Non-dominant Legs of Volleyball players at $60 \% \mathrm{~s}$ and $120 \% \mathrm{~s}$

\begin{tabular}{llcccc}
\hline & & $\begin{array}{c}\mathbf{6 0}^{\circ} / \text { s Bilateral } \\
\text { Flexion }\end{array}$ & $\begin{array}{c}\mathbf{6 0} / \text { s Bilateral } \\
\text { Extension }\end{array}$ & $\begin{array}{c}\mathbf{1 2 0}^{\circ} / \text { s Bilateral } \\
\text { Flexion }\end{array}$ & $\begin{array}{c}\mathbf{1 2 0} / \text { s Bilateral } \\
\text { Extension }\end{array}$ \\
\hline Dynamic & $\mathbf{r}$ &,- 032 &,- 137 &,$- 628 *$ & $\mathbf{- , 5 7 1}$ \\
Balance & $\mathbf{p}$ &, 922 &, 672 & $\mathbf{, 0 2 9}$ & $\mathbf{0 5 3}$ \\
\hline
\end{tabular}

$* \mathbf{p}<0.05$

In Table 4, it was seen that there was no statistically significant relationship between the dynamic balance performance of the volleyball players and the bilateral differences of the flexor and extensor muscles at the angular velocity of $60^{\circ} / \mathrm{s}$ ( $>0.05$ ), and there was statistically significant relationship between the bilateral differences of the flexor and extensor muscles at $120 \% \mathrm{~s}$ angular velocity $(\mathrm{p}<0,05)$. It was seen in squat movement that there was no statistically significant relationship between dynamic balance performance and bilateral differences of extensor muscles at angular velocities of $60 \%$ and $120 \%$ ( $>0,05)$; and there was a statistically significant relationship between bilateral differences of flexor muscles at angular velocities of $60 \%$ and $120 \% \mathrm{~s}(\mathrm{p}<0,05)$. 
Table 5. The Relationship between Hamstring and Quadriceps Muscle Power Ratio and Dynamic Balance of the Dominant and Non-dominant Legs of Volleyball Players at $60 \%$ and $120 \%$ s Angular Velocity

\begin{tabular}{lccccc}
\hline & & $\begin{array}{c}\text { Dominant } \\
\mathbf{6 0} / \mathbf{s ~ H / Q}\end{array}$ & $\begin{array}{c}\text { Non-dominant } \\
\mathbf{6 0} \% \text { /s H/Q }\end{array}$ & $\begin{array}{c}\text { Dominant } \\
\mathbf{1 2 0} \% \mathbf{s} \mathbf{H} / \mathbf{Q}\end{array}$ & $\begin{array}{c}\text { Non-dominant } \\
\mathbf{1 2 0} / \mathbf{s} \mathbf{H} / \mathbf{Q}\end{array}$ \\
\hline Dynamic & $\mathbf{r}$ &,- 302 &,- 084 &,- 126 &,- 186 \\
Balance & $\mathbf{p}$ &, 340 &, 795 &, 696 &, 563 \\
\hline
\end{tabular}

p>0.05

In Table 5, there was no statistically significant relationship between dynamic balance performance of volleyball players and H/Q force ratio of dominant and non-dominant leg at angular velocity of $60^{\circ} / \mathrm{s}$ and $120 \% \mathrm{~s}(\mathrm{p}>0.05)$. In squat movement, there was no statistically significant relationship between dynamic balance performance and H/Q force ratio of dominant and non-dominant leg at angular velocity of $60 \%$ and $120 \% \mathrm{~s}(\mathrm{p}>0.05)$.

\section{Discussion and Conclusions}

When the literature is analysed, some studies show a significant relationship between H/Q muscle strength and balance, while Soyuer et al. (2006) showed in their study that there is a relationship between balance and lower extremity muscle strength. Mohammadi et al. (2012) found out that the strength-training program for lower extremity in young male athletes increased leg strength and consequently increased their dynamic balance performance. Çelenk et al. (2015) found out in their study that quadriceps muscle strength was associated with dynamic balance performance, while hamstring muscle strength had no effect on balance performance. Bulgay and Polat (2017) stated in their study on wrestlers that balance performance is a significant relationship with leg muscle strength. Akarçeşme and Aktuğ (2018) determined in their study on female volleyball players that the increase in isokinetic quadriceps muscle strength of the hamstring and quadriceps muscle strength at the dominant leg at angular velocities of $60 \% \mathrm{~s}$ at $180 \%$ improved the dynamic balance performance.

There are also some studies showing that there is no significant relationship between H/Q muscle strength and balance. Kapşigay et al. (2013) could not find a statistically significant difference between the dominant and non-dominant leg strength and the body balance in their study on footballers. Göktepe (2016) could not find any significant difference between the dominant and non-dominant leg strengths and balance performances of football players ( $p>0.05)$. Gökten (2016) did not find any difference between hamstring / quadriceps ratios and balance variables in his study on U17-U18 saloon and beach volleyball players ( $p>0.05$ ). In this study, it was found that there was no statistically significant relationship between the balance of $\mathrm{H} / \mathrm{Q}$ muscle strength and dynamic balance of the isokinetic leg forces of the volleyball players at the angular velocity of at $60 \%$ and $120 \%$ s $(\mathrm{p}>0.05)$, and there were some similarities with the studies in the literature.

Although there are some studies evaluating the balance and leg strength, it hasn't been revealed yet to what extent leg bilateral differences are influential on balance and such studies are limited.

In his study, Bakırhan (2007) found a significant correlation between bilateral force difference and dynamic balance. A statistically significant relationship was detected between volleyball players' hamstring and quadriceps bilateral muscle strength difference and dynamic balance performance at angular velocities of $120^{\circ} / \mathrm{s} \quad(\mathrm{p}<0,05)$. No statistically significant relationship was detected between volleyball players' hamstring and quadriceps bilateral muscle strength difference and dynamic balance performance at angular velocities of $60 \% \mathrm{~s}(\mathrm{p}>0.05)$.

Consequently, in this study, it is thought that the difference of bilateral muscle strength at the angular velocity of $120^{\circ} / \mathrm{s}$ has a significant effect on balance performance that constitutes the basis of performance in all branches and which is important in preventing injury.

\section{Suggestions}

It is seen that volleyball players only strengthen their dominant muscles in their strength training. In addition, it is thought that non-dominant muscles should also be strengthened at appropriate rates in order to provide appropriate bilateral difference. By this means, the balance performance increases and the risk of injury that is an expensive and difficult process decreases.

\section{References}

Akarçeşme, C., \& Aktuğ, Z. B. (2018). Investigation of the Effect of 14-week Volleyball Training on Isokinetic Knee Muscle Force and Dynamic Balance Performance, Inonu University, Journal of Physical Education and Sports Sciences (IÜBESBD), 5(1), 33-40. e-ISSN: 2148-6786. 
Bakırhan, S. (2007). Unilateral ve Bilateral Total Diz Artroplastisi Uygulanan Hastaların, Fiziksel Performans Statik-Dinamik Denge yönünden Karşılaştırılması. Doktora Tezi, Dokuz Eylül Üniversitesi, Sağlık Bilimleri Enstitüsü, İzmir.

Bulgay, C., \& Polat, S. Ç. (2017). Investigation of the Relationship between Leg Force and Balance Performance of the Wrestlers at the Elite Level, Inonu University, Journal of Physical Education and Sport Sciences (IÜBESBD), 4(3), 59-67.

Çelenk, Ç., Marangoz, İ., Aktuğ, Z. B., Top, E., \& Akıl, M. (2015). The effect of quadriceps femoris and hamstring muscular force on static and dynamic balance performance. International Journal of Physical Education Sports and Health, 2(2), 323-325.

Derviseviç, E., \& Hadziç, V. (2012). Quadriceps and hamstrings strength in team sports: Basketball, football and volleyball. Isokinet Exerc Sci. 20(4), 293-300. https://doi.org/10.3233/IES-2012-00483

Foss, K. D. B., Myer, G. D., \& Hewett, T. E. (2014). Epidemiology of basketball, soccer, and volleyball injuries in middle-school female athletes. The Physician and Sportsmedicine. 42(2), 146-153. https://doi.org/10.3810/psm.2014.05.2066

Gökten, H. (2016). U17-U18 Age Group Beach and Hall Volleyball National Team Infrastructure Preparedness of Some Variables Obtained from Athletes Receiving Training Training, Bartin University Institute of Educational Sciences, Master Thesis, Bartin.

Göktepe, M. (2016). Futbolcularda Dominant ve Non-dominant Ayak Statik Denge Parametrelerinin Karşılaştırılması, International Journal of Science Culture and Sport (IntJSCS), 4(SI 1), 260-269. https://doi.org/10.14486/IntJSCS554

Hewett, T. E., Lindenfeld, T. N., Riccobene, J. V., \& Noyes, F. R. (1999). The effect of neuromuscular training on the incidence of knee injury in female athletes a prospective study. The American journal of sports medicine. 27(6), 699-706. https://doi.org/10.1177/03635465990270060301

Hewett, T. E., Torg, J. S., \& Boden, B. P. (2009). Video analysis of trunk and knee motion during non-contact anterior cruciate ligament injury in female athletes: lateral 75 trunk and knee abduction motion are combined components of the injury mechanism. Br J Sports Med. 43(6), 417-422. https://doi.org/10.1136/bjsm.2009.059162

İbiş, S., İri, R., \& Aktuğ, Z. B. (2015). The effect of female volleyball players' leg volume and mass on balance and reaction time. International Journal of Human Sciences, 12(2), 1296-1308. https://doi.org/10.14687/ijhs.v12i2.3319

İşleğen, Ç., Karamızrak, O., Ertat, A., \& Varol, R. (1989). Some Health Inspection Results, Body Composition and Physical Fitness Characteristics of Young National Football Teams. Journal of Sports Medicine, 24(3), 71-77.

Kapşigay, B. Özgül, B., Sarı, Z., \& Polat, M. G. (2013). Investigation of the Effect of Dominant and NonDominant Lower Limb on Body Balance in Football Players, III. National Sports Physiotherapists Congress, 7-9 November, Ankara.

Kong, P. W., \& Burns, S. F. (2010). Bilateral difference in hamstrings to quadriceps ratio in healthy males and females. Phys Ther Sport, 11(1), 12-17. https://doi.org/10.1016/j.ptsp.2009.09.004

Magalhaes, J., Oliveira, J., Ascensao, A., \& Soares, J. (2004). Concentric quadriceps and hamstrings isokinetic strength in volleyball and soccer players. J Sports Med Phys Fitness, 44, 119-25.

Matthews, M. J., Matthews, H., Yusuf, M., \& Doyle, C. (2016). Traditional Martial Arts Training Enhances Balance and Neuromuscular Control in Female Modern Martial Artists. J. Yoga Phys. Ther., 6(228), 2-5. https://doi.org/10.4172/2157-7595.1000228

Mohammadi, V., Alizadeh, M., \& Gaieni, A. (2012). The Effects Of Six Weeks Strength Exercises On Static and Dynamic Balance Of Young Male Athletes. Social Behavioral Sci., 31, 247-250.

https://doi.org/10.1016/j.sbspro.2011.12.050

Moraru, C., Neculaeş, M., \& Hodorcă, R. M. (2014). Comparative study on the balance ability insporty and unsporty children. Social Behavioral Sciences, 116, 19-22. https://doi.org/10.1016/j.sbspro.2014.01.819

Pappas, E., Hagins, M., Sheikhzadeh, A., Nordin, M., \& Rose, D. (2007). Biomechanical differences between unilateral and bilateral landings from a jump: gender differences. Clin J Sport Med., 17(4), 263-268. https://doi.org/10.1097/JSM.0b013e31811f415b

Rosene, M. R., Fogarty, T. D., \& Mahaffey, B. L. (2001). Isokinetic hamstrings:quadriceps ratios in intercollegiate 
athletes. Journal of Athletic Training, 36(4), 378-383.

Sayers, M. (2000). "Running techniques for field spot players". Sports coach. 26-27.

Soyuer, F., \& Mirza, M. (2006). Relationship Between Lower Extremity Muscle Strength And Balance İn Multiple Sclerosis. Journal of Neurological Sciences (Turkish), 23(4), 257-263.

Willigenburg, N. W., McNally, M. P., \& Hewett, T. E. (2015). Quadriceps and hamstrings strength in athletes. In: Reading CC, Brochers JR, editors. Hamstrings and Quadriceps Injuries in Athletes: A Clinical Guide, New York, Springer Science+Business Media. https://doi.org/10.1007/978-1-4899-7510-2_2

\section{Copyrights}

Copyright for this article is retained by the author(s), with first publication rights granted to the journal.

This is an open-access article distributed under the terms and conditions of the Creative Commons Attribution license which permits unrestricted use, distribution, and reproduction in any medium, provided the original work is properly cited. 